\title{
Larval Colonizing Strategies in Marine Benthic Invertebrates*
}

\author{
S. Obrebski \\ Tomales Bay Marine Laboratory, Marshall, California 94940, USA
}

\begin{abstract}
A model of colonizing strategy in planktonic larvae of marine invertebrates is proposed in which reproductive efficiency is measured by the frequency of adult habitat patches colonized by a least one larva divided by adult reproductive effort. Conditions leading to alternative energy allocation to either fuel larval habitat search or to support more efficient metamorphosis and post-larval survival are examined. Three predictions emerge: (1) Benthic organisms whose larvae colonize abundant habitat patches should lose larval stages more often than those whose larvae colonize rare patches; (2) prolonged larval life should be associated with colonization of rare patches; and (3) along clines of increasingly unfavorable conditions for larval survival, energy should be allocated to modifications reducing larval mortality and increasing energy reserves for metamorphosis and early post-larval development. Aspects of larval biology and data needs are discussed.
\end{abstract}

\section{INTRODUCTION}

Marine invertebrates disperse with larvae that settle in new areas and vary in the duration of pelagic life and modes of development (e.g. Thorson, 1961; Mileikovski, 1971; Chia, 1974). Planktotrophic larvae feed and hatch from smaller eggs than lecithotrophic larvae which do not feed. Simple models have been proposed to account for the evolutionary stability of these modes of development (Vance, 1973a, b) and loss of the larval phase (Menge, 1973). The purpose of this paper is to introduce a new model of larval dispersal and colonizing strategy which suggests relationships between developmental characteristics and conditions leading to extinction of the larval phase. These relationships have not been studied by larval biologists.

Larval dispersal would be advantageous if adult habitats were continuously deteriorating and unpredictable (Roff, 1973, 1974a, b; Strathmann, 1974). Planktotrophic development may be advantageous by increasing larval dispersal range and fecundity but may result in higher larval mortality and longer duration of larval life. Lecithotrophic development may increase larval survival but lower adult fecundity and reduce the dispersal range.

It is not clear what the duration of larval life ought to be to insure adequate dispersal. The optimal duration

\footnotetext{
- Contribution No. 5 from the Tomales Bay Marine Laboratory
}

of larval life may not only be that necessary to insure adequate dispersal. It is intuitively apparent that both larval and adult environments could affect larval colonizing strategy and that along gradients of increasingly unfavorable conditions for larval survival and development, larval stages are more likely to be retained by species living in relatively rare adult habitats. But it is not immediately clear what features of larval biology would optimize colonization of adult habitats. Would it be better to expend larval resources on efficient habitat search or rather to improve metamorphosis and early post-larval survival? The model presented here links the duration of planktonic larval life with mortality and developmental rates, alternative energy demands during habitat search and metamorphosis and with habitat abundance. Predictions are made about the conditions leading to extinction of dispersal with larvae, conditions favoring evolution of prolonged larval life, and changes in biological features of larvae along environmental clines.

\section{TIME, ENERGY AND DEVELOPMENT}

Metamorphosis and early post-larval survival require energy, although the amount may vary. Many invertebrates undergo extensive morphological change after settling, others metamorphose while still pelagic (Strathmann, 1978). Many prosobranch snails do not change much at metamorphosis while nudi- 
brach larvae have little resemblance to juveniles (Bonar, 1976). In oysters and mussels, larval structures are resorbed or transformed into adult feeding structures. (Bayne, 1971; Hickman and Gruffyd, 1971). Larvae of Ostrea lurida store lipids which increase from $9 \%$ of organic body weight at hatching to $23 \%$ just before metamorphosis, decreasing back to $9 \%$ during metamorphosis and then remaining constant for the next 25 days (Holland and Spencer, 1973). Lipids are the main energy reserve during starvation at metamorphosis. Loss of feeding efficiency may accompany metamorphosis as in Palaemon serratus in which it is reduced by $50 \%$ (Reeve, 1969), and in juvenile sea stars which are small, with only a few tube feet per arm, and consequently suffer a delay in the time required to capture their first meal (Strathmann, 1971). In the worm Spirorbis spirorbis, larvae construct a mucoid tube and attachment platform before settling (Nott, 1973). Copious amounts of mucus are used and the larvae also make mucus threads for attaching to the substrate while examining it is for suitability.

If energy is required to fuel habitat search and metamorphosis, lecithotrophic larvae may need to budget and apportion it between alternative demands quite precisely, since the time spent dispersing as larvae is highly dependent upon egg size and the amount of yolk available. Planktotrophic larvae can regain lost reserves by additional feeding, so that their larval lifetime may depend upon feeding efficiency, and the availability of sufficient reserves to permit habitat search and successful metamorphosis. The allocation of reserves between habitat search and metamorphosis may also need to be budgeted. For instance, if searching only costs Spirorbis larvae expenditure of a little mucus for threads, most is available for tubes, possibly reducing post-larval mortality, but if searching also requires energy for swimming and making many threads, less mucus would be available for tubes and post-larval survival might decrease. The optimal allocation of energy during larval colonization of adult habitats may vary in different environments and may depend upon the currency being maximized by natural selection, as discussed in the model of colonizing strategy that follows.

\section{MODEL OF COLONIZING STRATEGY}

Adult habitats being colonized by larvae vary in space and time and adults cannot leave habitat patches after settling, or are limited in their movements. I propose a simple dichotony between two types of patches. In $S$-patches ( $S$ for survival), adult survival varies between very low and very high probabilities, while in $D$-patches ( $D$ for death) survival is always very low or zero. An optimum colonizing strategy would partially involve maximizing the number of larvae issuing from a single episode of reproduction by an individual organism that settles in $S$-patches, because some of these patches, albeit a small number, will favor survival of juveniles to maturity. This would hold especially if future survival cannot be predicted for a patch at the time of settling. The distinction between $S$ - and $D$-patches can be clear. For barnacles, sediments are $D$-patches, rocks and pilings are $S$-patches; for mud worms, coarse sediments and rocks are $D$ patches, muds are S-patches; for Spirorbis species, fucoid algae are $S$-patches, although they can distinguish between different types of algae (Scheltema, 1974; Doyle, 1975).

I adopt this simplification in distinguishing patch types partly to avoid mathematical complexity in postulating various frequency distributions of patch types that vary continuously in adult survival probabilities. The environment is seen here as coarse grained in the sense of Levins (1968), but only in the context of broad habitat differences encountered by larvae. Thus, barmacles live on hard substrates and do not move to coarse substrates, etc.

The optimum time spent in the plankton by a larva must include consideration of planktonic mortality. Let $m$ be the instantaneous mortality rate of a cohort of larvae, $N$ their number, and let

$\partial N / \partial t=-m N$ or $N_{t}=N_{o} \exp (-m t)$

where $N_{t}$ is the number remaining out of an initial cohort of $N_{o}$ larvae born at time $t=0$ and remaining in the plankton for some time $t$.

Let $S$ and $D$ represent the number of $S$ - and $D$ patches, respectively, in the settling range of the larvae, where the total number of patches $T=S+D$. The patches may be of a size corresponding to the local activity of the adult and $T$ represents the total area available for settling. Let $B$ be the probability of settling in a $D$-patch, and $A$ the probability that a larva survives in an $S$-patch to maturity. Values of $A$ and $B$ will depend upon the way larvae allocate energy between habitat search and metamorphosis. If little energy is used in habitat search, $B$ will be large and $A$ correspondingly high. That is, when habitat search is not emphasized, more larvae will settle in $D$-patches (increasing $B$ ) but those that settle in $S$-patches will have a better chance of successfully metamorphosing and surviving early post-larval life (due to higher $A$ ). If larvae respond to some environmental cues and search out $S$-patches by active swimming and otherwise use energy in habitat search that would not be available for metamorphosis, $B$ will be lower, but so will $A$. While fewer larvae will settle in $D$-patches (due to lower $B$ ), survival $S$-patches will be lower (due to lower 
A). The probability $A$ depends on how resources are applied to metamorphosis and early post-larval survival. The probability $B$ depends on energy allocated to habitat search. If $B$ is not zero, some of the larvae will settle in $D$-patches and it is assumed that the rest will settle in $S$-patches if they do not die.

Assuming that the larvae are distributed amongst $S$ patches according to the Poisson distribution, the proportion of $S$-patches in which at least one larva survives to maturity, $F$, is given by the relation

$F=1-\exp \left\{-(A / S) N_{o} \cdot \exp [-(m t+B D)]\right\}$

The Poisson distribution is chosen to simplify the model as it depends on one parameter, the mean, and this simplifies the mathematics. Equation (2) is obtained as follows. The Poisson frequency of patches settled by at least one larva is obtained from the term $1-\exp (-U)$ where $U$ is the mean number of larvae per patch. The mean is calculated as follows: The probability that an individual larva does not settle in a $D$ patch is $(1-B)$ and the probability that it does not settle in any of the $D$-patches is $(1-B)^{D}$ which approaches $\exp (-B D)$ when $D$ is very much larger than $B$, as would be the case. From Equation (1), the total number of larvae surviving to settle is $N_{0} \exp [-(m t+B D)]$. If there are $S S$-patches, the average number of larvae surviving to maturity will be $(A / S) N_{0} \exp [-(m t+B D)]$ which is substituted for $U$ required in Equation (2).

I know of no data for marine larvae to test the foregoing model, but laboratory data on frequencies of host snails infested by schistosome miracidia larvae are available. These show agreement with the model as shown in Figure 1.
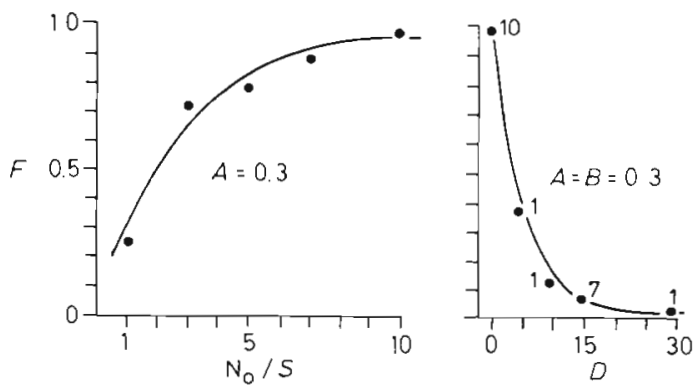

Fig. 1. Fitting Equation (2) to experimental observations of frequencies of hosts colonized by miracidia larvae. $S$ indicates survival; $D$, death; $F$ : survival to maturity. Larvae were released into a chamber containing hosts ( $S$-patches) in which they survive and 'decoy' hosts ( $D$-patches) in which they may die. Decoys were interposed between the release point of larvae and hosts. Numbers of larvae per host were varied $\left(N_{\sigma} / S\right)$. Left: $D=0 ; m$ assumed to be negligible, Right: $D$ varied for $N_{o} / S=10 ; m$ assumed to be negligible. Curves for values of $A$ and $B$ indicated are shown. Left next to points: number of observations. Points on left are means. For other details see Chernin (1968) and Chernin and Perlstein (1969).

Note that when $D$ is high, $F$ is substantially reduced

\section{EFFICIENCY OF THE LARVAL COLONIZING STRATEGY}

I propose to measure the reproductive efficiency of the colonizing strategy as the proportion of $S$-patches colonized by at least one larva surviving to maturity divided by the number of larvae released in one episode of reproduction, or the ratio $F / N_{0}$, or any ratio correlated with it. This measures the success of colonization of adult habitats per unit of reproductive effort. Selection will maximize this ratio. Equation (2) may be rearranged algebraically to

$\frac{|\ln (1-F)|}{N_{o}}=(A / S) \exp [-(I n t+B D)]$

the ratio on the left increasing directly with increasing $\mathrm{F} / \mathrm{N}_{0}$ and representing reproductive efficiency as defined. It is more convenient to use the logarithm of the ratio in Equation (3) so that reproductive efficiency (henceforth $R E$ ) becomes, after taking logarithms on both sides

$R E=\ln \left[\frac{|\ln (1-F)|}{N_{o}}\right]=\ln A-\ln S-m t-B D$

Selection will maximize RE in Equation (4) which is most sensitive to the planktonic mortality rate $(m)$, time spent as a pelagic larva ( $t)$, the number of $D$-patches $(D)$ and the probability of settling in a $D$-patch (B). $R E$ is less sensitive to the logarithmic terms, the number of $S$-patches (S) and the probability of surviving in an $S$ patch to maturity (A). Of particular interest is the result that when $D$ is large, reduction of $B$ to a minimum can substantially increase $R E$. Therefore, effective habitat recognition is essential to maximizing $R E$. Extensive literature on factors affecting larval settlement is reviewed by Scheltema (1974). Presence of algalbacterial films attracts many larvae to settle but repels others. Organic constituents of sediments, including microorganisms, are probably most important in affecting larval settlement. Some species of Spirorbis are very specific in choosing between calcareous or fucoid algae for settlement. Spirorbis spirorbis prefers fucoids over laminariales. Other larvae settle in response to presence of adult prey or species associated with adults. Juvenile echinoderms settle and remain on tubes of the polychaete Phyllochaetopterus prolifica and rarely elsewhere, moving out after a few years. Thus, larvae of Mediaster aequalis are most effectively induced to settle on the tubes of this worm, while adults are found on mud, snad, cobble and rock surfaces. The worm is believed to harbor food for small asteroids with generalized diets (Birkeland et al., 1971). The model reflects the selectivity of larvae for settling sites, in particular their choice of substrates where post-larval survival is high (i. e. avoidance of $D$ patches and minimization of the probability $B$ ). 


\section{OPTIMAL LARVAL LIFETIME}

The optimal larval lifetime can be obtained by substituting time-dependent functions for $A$ and $B$ in Equation (4). It is assumed that during the course of larval development $A$ increases exponentially and $B$ decreases exponentially with time, according to the relations $A=\exp \left(d_{A} t-c\right)$ and $B=\exp \left(-d_{B} t\right), d_{A}$ and $d_{B}$ being appropriate developmental rates and $c$ being chosen larger than $d_{A} t$ so that $A$ does not exceed 1. Substitution of these functions for $A$ and $B$ in Equation (4) and solving for $t$ maximizing $R E$ (from calculations of $\partial R E / \partial t$ and $\partial^{2} R E / \partial t^{2}$ and solving for $t$ maximizing $R E$ using the first derivative set to 0 ) yields the relation

$t_{\text {opt }}=\left(1 / d_{B}\right)\left[\ln d_{B}+\ln D-\ln \left(m-d_{A}\right)\right]$

from which the optimal larval lifetime, $t_{\text {opt }}$ can be computed. Values of $t_{\text {opt }}$ above 0 will obtain as long as

$D>\left(m-d_{A}\right) / d_{B}$

(or $D+1>m / d$ when $d=d_{A}=d_{B}$ )

and will be less than 0 when these inequalities are reversed. The behavior of Equation (5) is shown in

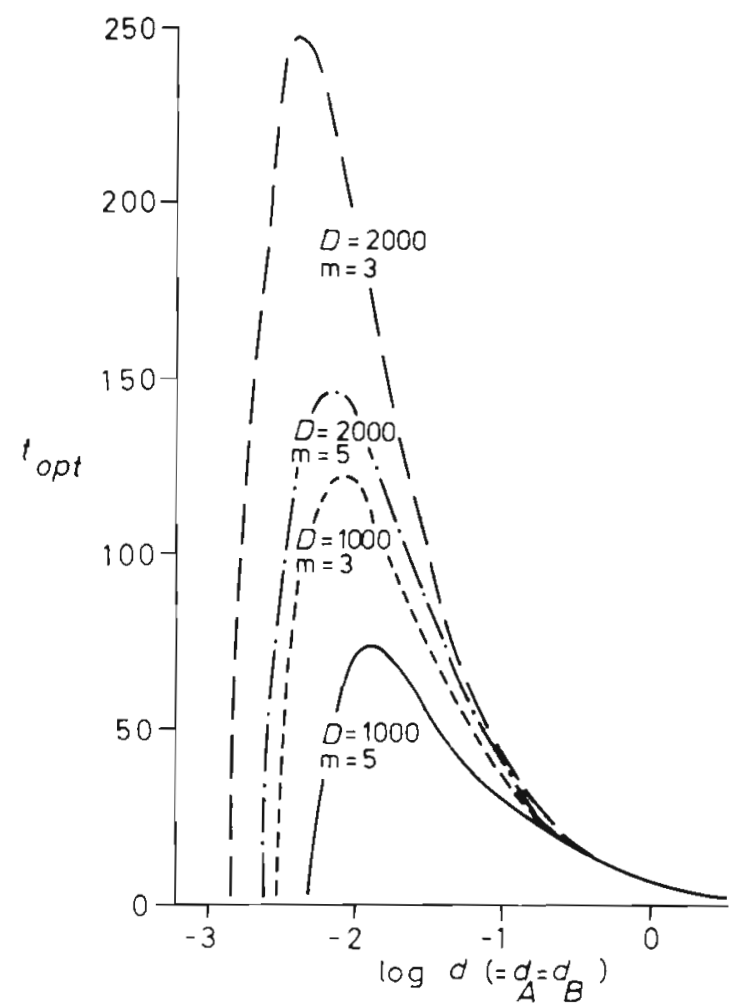

Fig. 2. Changes in $t_{\text {opt }}$ (optimal larval life time) along gradient of decreasing developmental rate for different values of $m$ and $D$. The behavior of Equation (5) is the same for other values of the variables when $d_{A}$ is not set equal to $d_{B}$. Curves do not go to zero on the right, as indicated in text. Note that different combinations of variables yield the same values of $t_{\text {opt }}$
Figure 2. Along a gradient of decreasing developmental rates $t_{o p t}$ first increases gradually to a maximum and then rapidly decreases to $O$. Larval lifetimes are longest either when $m$ and $d_{B}$ are small, $D$ and $d_{A}$ are large or when $d_{A}$ approaches $m$ very closely but is less than $m$ in which case $t_{o p t}$ approaches infinity. Note that $t_{\text {opt }}$ is most sensitive to changes in $d_{B}$ which affects the probability of not settling in $D$-patches, $B$. I assume that $m$ is always greater than $d_{A}$. Mortality and developmental rates vary with temperature, salinity and other factors under laboratory conditions which are often extrapolated to presumed effects in nature (for reviews consult 'Marine Ecology' Volume I: Kinne, 1970, 1971; see also Lough, 1975). Natural mortality rates of larvae are generally agreed to be exceedingly high, although some low rates have been reported (Lucas, 1975). Estimates of larval mortality rates are usually precluded because many populations may contribute to a particular larval population being sampled, and there is no way that a cohort of larvae can be sampled through time. Developmental rates are known exclusively from laboratory studies and are highly temperature dependent. Thus, natural larval lifetimes cannot be estimated and consequently this model cannot be used to test specific hypotheses about the exact duration of larval lifetimes. However, conditions leading to extinction of larvae $\left(t_{\text {opt }}<0\right)$ or unusually long larval lifetimes can be investigated.

\section{EXTINCTION OF LARVAE}

Pelagic development is known to decrease with increasing latitude and this has been attributed to increase in mortality and decrease in developmental rates due to reduced food availability and temperature at high latitudes, phytoplankton being present for only short periods of time (Thorson, 1950), although Underwood (1974) doubts this interpretation, citing evidence of synchrony between spawning and phytoplankton abundance. But such synchrony might increase larval competition for food on a resource available for a short period of time. From the inequalities in Equation (6), it is predicted that in the gradients described, species inhabiting abundant habitats (low $D$, large $S$ ) are more likely to lose larvae when the inequalities are reversed. For example, in a particular taxon, species inhabiting widespread habitats should lose larvae at a faster rate than those in rare habitats. This prediction could be tested if habitats could be arranged in decreasing order of abundance. A possible ordering from high to low abundance might be: coastal sediment (sand and mud) communities > rocky intertidal communities $>$ specialized substrates (such as worm tubes, shells, particular algae). This prediction from 
the model parallels the intuitive expectation that if dispersal with larvae is advantageous because of continuous deterioration of adult habitats, perpetuation of the larval phase would depend upon habitat abundance. Adults specialized for life on a rare habitat would have to maintain larval dispersal even under conditions that are increasingly unfavorable for larval survival, or they would become extinct. This might make such specialists increasingly subject to large fluctuations in recruitment.

Some data does indeed suggest that larvae are lost more frequently amongst species living in abundant habitats. Among prosobranch snails over $90 \%$ of tropical shore species have planktonic larvae, while in deeper waters 25-69\% hatch metamorphosed, and among muricacean snails rocky shore species tend to retain larvae in comparison with shallow water sand species (Spight, 1977). According to Barnes (1963), sand and mud dwelling ascidians tend to lose their larvae in comparison to hard surface forms, although the source of this data is not cited. More comprehensive information on relationships between habitat type and reproductive characteristics of marine invertebrates is needed to test the foregoing hypothesis.

\section{CHANGES IN LARVAL BIOLOGY ALONG ENVIRONMENTAL GRADIENTS}

Along gradients of increasing larval mortality and decreasing developmental rates, larvae will be retained $\left(t_{\text {opt }}>0\right)$ as long as $D>\left(m-d_{A}\right) / d_{B}$ (Equation $6)$, that is, as long as $m$ increases at a slower rate than $d_{B}$ decreases and $d_{A}$ decreases more slowly than $d_{B}$. In species that retain larvae, $m$ will become smaller relative to $d_{A}$ and $d_{A}$ will become relatively larger than $d_{B}$. It is expected that larval features associated with decreasing mortality rate will therefore become more prominent. This might include features that reduce larval susceptibility to predation such as increasing larval size, shell thickness, size of setae or spines, and perhaps tendencies to become unpalatable to predators by production of specific chemicals. Larval features associated with increased $d_{A}$ relative to $d_{B}$ will increase the amount of energy allocated to metamorphosis and early post-larval survival and decrease the amount spent on habitat search. Such features might include increase in the accumulation of lipids or other energy storage products prior to metamorphosis, increased thickness of protective tubes and shells in metamorphosed juveniles, more rapid metamorphosis, more passive methods of habitat search, slower swimming speed, more efficient or widespread resorption of larval organs during metamorphosis, reduction of some larval structures such as the pediveliger foot, and so on.

Trends in larval characteristics along latitudinal or other clines have not been studied. Large tentaculate tornaria larvae of enteropneusts are reported from tropical waters poor in food around oceanic islands while most tropical non-tentaculate forms occur only near continents (Strathmann and Bonar, 1976). Variation in larval biology has been observed, but not along clines. Significant additive genetic variance in larval growth rate and light-dark preferences have been reported (Doyle, 1974; Newkirk et al., 1977; for review see 'Marine Ecology', Volume II: Gooch, 1975). Genetic interaction in growth rate with salinity has been found in mussel larvae (Innes and Haley, 1977). This suggests that variation within species in larval features along clines may occur. Variation between species reflecting possible differences in energy allocation includes loss of the velum in some larvae subject to delay in metamorphosis and not in others (Culliney, 1974), Placopecten magellanicus losing the velum but not Mytilus edulis: variation in size at which the pediveliger foot is active between Modiolus modiolus and Mytilus edulis (de Schweinitz and Lutz, 1976); variation in the size of juveniles carried by precociously metamorphosing echinoderm larvae (Strathmann, 1971); variation in the age at which the barnacle cement gland becomes active and amounts of cement produced to anchor pediveliger in oysters (Cheung and Nigrelli, 1972; Cranfield, 1974); and differences in larval respiration rates and swimming activity (Crisp, 1974). In general, when features associated with habitat search diminish in importance, those enhancing metamorphic success or larval survival should increase. Many of the features mentioned have not been studied with the precision and in the quantity required to test the above hypothesis.

\section{PROLONGED LARVAL LIFETIMES}

Calculations show that similar larval lifetimes can occur at different values of $D, m, d_{A}$ and $d_{B}$ (Fig. 2). This, and the sensitivity of developmental rates to temperature and other variables, make it impossible to test specific predictions about optimal larval lifetimes. However, conditions leading to extremely prolonged larval lifetimes can be deduced. These will occur when $\left(m-d_{A}\right)$ and $d_{B}$ are very small and $D$ is very large. Larvae with these characteristics will have low mortality rates, inhabit very rare adult habitats, and allocate resources to metamorphosis and post-larval survival rather than habitat search. That is, they will have characteristics of larvae surviving at the unfavorable 
ends of environmental clines described in the preceding section.

Scheltema (1971) describes 10 species of prosobranch veligers occurring in North and tropical Atlantic open waters, the adult snails occurring on both coasts in tropical and warm temperate shelf waters. Two of the species were able to delay metamorphosis over three months in the laboratory. The adult habitat of only one of these species is mentioned; that of Pedicularia sicula which is found only on stylasterine hydrocorals. Mediaster aequalis whose larvae settle on tubes of the polychaete Phyllochaetopterus prolifica is able to delay metamorphosis for 14 months (Birkeland et al., 1971). The correlation between the ability to delay metamorphosis for prolonged periods and abundance of habitats settled by larvae needs to be studied more extensively.

\section{DISCUSSION}

It has been suggested that dispersal with larvae is advantageous when adult environments are continuously deteriorating (Strathmann, 1974; Roff, 1973, $1974 \mathrm{a}$, b) or when there is adult density-dependent mortality (Crisp, 1974). However, Hamilton and May (1977) show that adaptations for dispersal may also be advantageous in stable habitats. Experimental verification of these hypotheses could require comprehensive data on the population biology of many species.

Vance $(1973 \mathrm{a}, \mathrm{b})$ developed models in which RE was measured by the ratio of larvae surviving to metamorphosis per unit of calories expended in reproduction. Lecithotrophic and planktotrophic development were shown to be extremes maximizing $R E$, intermediate developmental modes being less efficient. Planktotrophy was predicted in environments where larval mortality was low and food abundant, lecithotrophy when these conditions were reserved. Benthic pre-feeding development was predicted when lecithotrophic developmental time was long and/or planktonic mortality was greater than benthic mortality, and planktonic pre-feeding development was predicted when these conditions were reversed. Testing the foregoing hypotheses would require data on planktonic and benthic larval mortality and developmental rates. Some workers doubt that evolution of the mode of reproduction is governed by energy considerations (see Underwood, 1974, and a reply by Vance, 1974; Strathmann, 1977).

The major emphasis in this paper has been to consider the evolutionary consequences of a colonizing strategy in which a measure of survival to reproduction divided by reproductive effort is the measure of reproductive efficiency. Extinction of a larval phase is pre- dicted for species inhabiting relatively common habitats when conditions for larval survival deteriorate. Prolonged larval lifetimes are predicted for species inhabiting rare habitats. Under increasingly unfavorable conditions for larval survival, due either to food shortage or slower development, species maintaining larval dispersal are predicted to develop larval habits and structures that minimize mortality due to predation or other factors, and which emphasize efficient metamorphosis and early post-larval survival over sophisticated and efficient habitat search capabilities. Comprehensive data for testing these predictions are lacking. There may be difficulties in measuring habitat abundances, especially amongst species that live in specific environments such as on particular corals or algae. Generally, broad differences in habitat abundance, such as those between soft sediments and rocky substrates, are easily discerned. Differences between adult habitats and larval settling habitats should be recognized. Since some echinoderms might settle on specific habitats and move out to other areas after a period of juvenile feeding (Birkeland et al., 1971), they might be classified as relatively rare habitat species. Measurements of trends in size or characteristics of some larval features along clines may be simple. For instance, size of spines, tentacles, or shells may be easily determined and compared. Amounts of lipid in reserve prior to metamorphosis may also be easily measured. It may be difficult, however, to obtain unambiguous quantitative data on the amount of energy expended during habitat search relative to the amount devoted to metamorphic activities.

The division of adult habitats into two distinct patch types may be an oversimplification in some cases. It was adopted in part to avoid a more complex model and may be in accord with the apparent general tendency of larvae to choose or avoid broad substrate categories. In an elegant study, Doyle (1975) showed that differences in attractiveness of algae to settling Spirorbis spirorbis larvae were related to substrate suitability. Fucus was preferred to Ascophyllum because the worms cannot cement as strongly to the latter alga on which mortality is higher in turbulent waters. Doyle treats settling behavior as an absorbing Markov chain, predicting whether larvae will exhibit habitat preference in essentially similar habitat types. In the present context, the algae on which Spirorbis settles are $S$-patches differing somewhat in predictability. Since these worms settle on algae, other substrates are $D$-patches.

Developmental rates are highly temperature dependent (Spight, 1977) and not measurable for larvae under natural conditions. The model predicts similar optimum larval lifetimes under varying conditions (Fig. 2). It would therefore be futile to attempt predic- 
tions of expected larval lifetimes. Mortalities of larvae in natural conditions are not easily measurable, if at all. However, habitat abundance and changes in larval biological characteristics among clines of the type described above may be more measurable and are emphasized in the predictions from the proposed model.

Prolonged larval lifetimes ought to be associated with increased larval feeding efficiencies. This point is not touched upon in the model presented here. For instance, among three species of Astropecten, A aranciacus, originating from the smallest egg, takes $90 \mathrm{~d}$ to metamorphose, the larva having well developed bipinnarial arms; A. scoparius, hatching from a larger egg, metamorphoses in $18 \mathrm{~d}$, and has a simple bipinnaria larva; and the lecithotrophic A. latespinosus metamorphoses in $5 \mathrm{~d}$ from an unusual barrel-shaped larva (Hörstadius, 1939; Komatsu, 1975; Oguro et al., 1976). Strathmann (1971) showed that clearance rates of echinoderm larvae increase with lengths of the ciliated bands and presumably larval size. Clearance rates of the asteroid Luidia foliolata increase with band length and approach the lower rates measured for small marine copepods. Strathmann states that energy is first devoted to developing feeding structures and then into development of the adult rudiment of the larva and suggests that echinoids and asteroids with planktotrophic larvae may combine maximum preparation for benthic colonization (with precocious development of adult rudiments before settling) and continued ability of the larva to feed. Possibly, carrying a juvenile so changes larval hydrodynamics as to reduce the energy required to swim to settling sites. Strathmann attributes resorption of the large larval body in asteroids to their small post-metamorphic size and difficulty in getting a first meal.

Menge (1975) attributed brooding in a sea star to the coadaptive consequences of competitor-induced small size, suggesting that a small species that broadcasts larvae could not produce enough offspring to replace itself. Assuming that larvae should be lost among rare habitat species, as suggested here, then it may also be that species having lost larval stages should also be smaller than competitors that retain larval dispersal.

Strathmann (1977) makes the important point that: ... 'accidents of ancestry ... place limits on adaptive variation'. He continues to state that some basic assumptions underlying models of reproductive strategy may hold for some and not other taxa. Differences in the ability to re-aquire a free-swimming larval stage are associated with the original type of larval feeding mechanism, degree of reorganization at metamorphosis, and other factors. Many invertebrates have apparently permanently lost an ancestral feeding larval stage (Strathmann, 1978). Spight (1977) shows that temperature and taxonomic affinity account for most of the variation in the duration of pre-hatching development in gastropods. If variation in reproductive characteristics frequently varies between but not within taxonomic groups, adaptive strategy models may be realistic only when many details of entire life histories are included. Such realism may yield more exact predictions but may result in unmanageable complexity in the models and in empirical verification of assumptions. These pitfalls are avoided in simple models (Strathmann, 1977).

The model of colonizing strategy proposed here is subject to possible changes in predictions when assumptions are changed about the distribution of larvae amongst patches, patch characteristics, and other features. The major objective has been to suggest that some biological features of larval development may be associated with larval colonizing strategy and to outline some of the difficulties associated with the study of dispersal in marine invertebrates.

Acknowledgements. I owe thanks to J. W. Hedgpeth, R. R. Strathmann, S. Stearns, S. Maxwell, J. A. Blake, R. Whitlatch, P. Obrebskí and R. Day for comments on earlier versions of the manuscript. This work was supported by grant GA-33438 from the National Sciences Foundation. This paper is dedicated to the memory of Ralph Gordon Johnson.

\section{LTTERATURE CITED}

Barnes, R. D. (1963). Invertebrate Zoology, Saunders, Philadelphia.

Bayne, B. L. (1971). Some morphological changes that occur at the metamorphosis of the larvae of Mytilus edulis. In D. J. Crisp (Ed.), Fourth European Marine Biology Symposium. Cambridge University Press, Cambridge. pp. 259-280.

Birkeland, C., Chia, F.-S. and Strathmann, R. R. (1971), Development, substratum selection, delay of metamorphosis and growth in the seastar Mediaster aequalis Stimpson. Biol. Bull. mar. biol. Lab., Woods Hole, 141, 99-108

Bonar, D. B. (1976). Molluscan metamorphosis: A study in tissue transformation. Am. Zool., 16, 573-591.

Chemin, E. (1968). Interference with the capacity of Schistosoma mansoni miracidia to infect the molluscan host. $J$. Parasit., 54, 509-516.

Chemin, E. and Perlstein, J. M. (1969). Further studies on the interference with the host finding capacity of Schistosoma mansoni miracidia. J. Parasit., 55, 500-508.

Cheung, P. J. and Nigrelli, R. F. (1975). Secretory activity of the cement gland in different developmental stages of the bamacle, Balanus eburneus. Mar. Biol., 32, 99-103.

Chia, F.-S. (1974). Classification and adaptive significance of developmental patterns in marine invertebrates. Thalassia jugosl., 10, 121-130.

Cranfield, H. J. (1974). Observations on the morphology of the mantle folds of the pediveliger of Ostrea edulis L. and their function during settlement. J. mar. biol. Ass. U. K, $54,1-12$.

Crisp, D. J. (1974). Energy relations of marine invertebrate larvae. Thalassia jugosl. 10, 103-120. 
Culliney, J. (1974). Larval development in the giant scallop, Placopecten magellanicus (Gmelin). Biol. Bull. mar. biol. Lab., Woods Hole, 146, 321-332.

De Schweinitz, E. H. and Lutz, R. A. (1976). Larval development of the northern horse mussel, Modiolus modiolus (L), including a comparison with the larvae of Mytilus edulis, L. as an aid in planktonic identification. Biol. Bull. mar. biol. Lab., Woods Hole, 150, 348-360.

Doyle, R. W. (1974). Choosing between darkness and light: The ecological genetics of photic behavior in the planktonic larva of Spirorbis spirorbis. Mar. Biol., 25, 311-317.

Doyle, R. W. (1975). Settlement of planktonic larvae: A theory of habitat selection in varying enviromments. Am. Nat., $109,113-126$.

Gooch, J. L. (1975). Mechanisms of evolution and population genetics. In O. Kinne (Ed.), Marine Ecology, Vol. II, Physiological Mechanisms, Part 1. Wiley, London. pp. 349-409.

Hamilton, W. D. and May, R. M. (1977). Dispersal in stable habitats. Nature, Lond., 269, 578-581.

Hickman, R. W. and Gruffydd, LL. D. (1971). The histology of the larva of Ostrea edulis during metamorphosis. In D. J. Crisp (Ed.), Fourth European Marine Biology Symposium. Cambridge University Press, Cambridge. pp. 281-294.

Hörstadius, S. (1939). Über die Entwicklung von Astropecten aranciacus L. Pubbl. Staz. zool. Napoli, 17, 221-312.

Holland, D. L. and Spencer, B. E. (1973). Biochemical changes in fed and starved oysters, Ostrea edulis L. during larval development, metamorphosis and early spat growth. $J$. mar. biol. Ass. U. K., 53, 287-298.

Innes, D. J. and Haley, L. E. (1977). Genetic aspects of larval growth under reduced salinity in Mytilus edulis. Biol. Bull. mar. biol. Lab., Woods Hole, 153, 312-321.

Kinne, O. (Ed.) (1970). Marine Ecology, Vol. I, Environmental Factors, Part 1, Wiley, London.

Kinne, O. (Ed.) (1971). Marine Ecology, Vol. I, Environmental Factors, Part 2, Wiley, London.

Komatsu, M. (1975). On the development of the sea star, Astropecten latespinosus Meissner. Biol. Bull. mar. biol. Lab., Woods Hole, 148, 49-59.

Levins, R. (1968), Evolution in Changing Environments, University Press, Princeton.

Lough, R. G. (1975). A reevaluation of the combined effects of temperature and salinity on survival and growth of bivalve larvae using response surface techniques. Fish. Bull. U. S., 73, 86-94.

Lucas, J. S. (1975). The larval stages of some Australian species of Halicarcinus (Crustacea, Brachyura, Hymenosomatidae). II Dispersal. Bull. mar. Sci., 25, 94-100.

Menge, B. A. (1975). Brood or Broadcast? The adaptive significance of different reproductive strategies in the two intertidal sea stars Leptasterias hexactis and Pisaster ochraceus. Mar. Biol., 31, 87-100

Mileikovsky, S. A. (1971). Types of larval development in marine bottom invertebrates, their distribution and ecological significance: a reevaluation. Mar. Biol., 10, 193-213.
Newkirk, G. F. Haley, L. E., Waugh, D. L. and Doyle, R. (1977). Genetics of larvae and spat growth rate in the oyster Crassostrea virginica. Mar. Biol., 41, 49-52.

Nott, J. A. (1973). Settlement of the larva of Spirorbis spirorbis L. J. mar. biol. Ass. U. K., 53, 437-453.

Oguro, C., Komatsu, M. and Kano, Y T. (1976). Development and metamorphosis of the sea star Astropecten scoparius Valenciennes. Biol. Bull. mar. biol. Lab., Woods Hole, 151, 560-573.

Reeve, M. R. (1969). Growth, metamorphosis, and energy conversion in the larvae of the prawn, Palaemon serratus. J. mar. biol. Ass. U. K., 49, 77-96.

Roff, D. A. (1974a). Spatial heterogeneity and the persistence of populations. Oecologia, 15, 245-258.

Roff, D. A. (1974b). An analysis of a population model demonstrating the importance of dispersal in a heterogeneous environment. Oecologia, 15, 259-275.

Roff, D. A. (1975). Population stability and the evolution of dispersal in a heterogeneous environment. Oecologia, 19, $217-237$.

Scheltema, R. S. (1971). Larval dispersal as a means of genetic exchange between geographically separated populations of shallow water benthic marine gastropods. Biol. Bull. mar. biol. Lab., Woods Hole, 140, 284-322.

Scheltema, R. S. (1974). Biological interactions determining larval settlement of marine invertebrates. Thalassia jugosl., 10, 263-296.

Spight, T. M. (1975). Factors extending gastropod embryonic development and their selective cost. Oecologia, 21, 1-16.

Strathmann, R. R. (1971). The feeding behavior of planktotrophic echinoderm larvae: mechanisms, regulation, and rates of suspension feeding. J. exp. mar. Biol., 6, 109-160.

Strathmann, R. R. (1974). The spread of sibling larvae of sedentary marine invertebrates. Am. Nat., 108, 29-44.

Strathmann. R. R. (1977). Egg size, larval development, and juvenile size in benthic marine invertebrates. Am. Nat., $111,373-376$.

Strathmann, R. R. (1978). The evolution and less of feeding larval stages of marine invertebrates. Evolution, Lancaster, Pa., 32, 894-906.

Strathmann, R. R. and Bonar, D. (1976). Ciliary feeding in tornaria larvae of Ptychodera flava (Hemichordata: Enteropneusta). Mar. Biol., 34, 317-324.

Thorson, G. (1950). Reproductive and larval ecology of marine bottom invertebrates. Biol. Rev., 25, 1-45.

Thorson, G. (1961). Length of pelagic larval life in marine bottom invertebrates as related to larval transport by ocean currents. In M. Sears (Ed), Oceanography. Publs Am. Ass. Advmt Sci, Washington. pp. 455-474.

Underwood, A. J. (1974). On models of reproductive strategy in marine benthic invertebrates. Am. Nat., 108, 874-878.

Vance, R. R. (1973a) On reproductive strategies in marine benthic invertebrates. Am. Nat., 107, 339-352.

Vance, R. R. (1973b). More on reproductive strategies in marine benthic invertebrates. Am. Nat., 107, 353-361.

Vance, R. R. (1974). Reply to Underwood. Am. Nat., 108, $879-880$.

This paper was presented by Emeritus Professor J. W. Hedgpeth; it was accepted for printing on October 3, 1979. 